\title{
Prevalence of Giardia and Cryptosporidium in young livestock and dogs in Magude District of Maputo Province, Mozambique
}

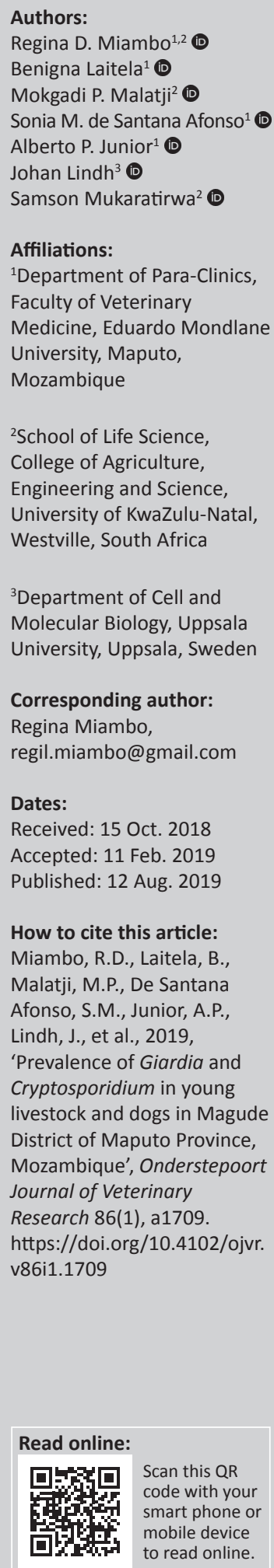

Background: Giardia and Cryptosporidium species are significant zoonotic parasites of humans and domesticated animals.

Objectives: The study aimed to determine the prevalence of Giardia and Cryptosporidium in livestock and dogs of the Magude District.

Method: The flotation technique (Willis), modified Ziehl-Neelsen (mZN) and direct and indirect immunofluorescence (DIF and IIF) techniques were applied to determine the prevalence of Giardia and Cryptosporidium species in faecal samples of dog pups (156), goat kids (60) and calves (480) from the Magude District of Mozambique from February to September 2015.

Results: Using Willis, IIF and DIF, the prevalence of Giardia in calves was 0\%, 8.1\%, and 6.0\%; in dogs $0.6 \%, 8.3 \%$ and $5.7 \%$ and for goats $0 \%$ and $13.3 \%$ (IIF was not performed), respectively. The prevalence of Cryptosporidium in calves using Willis, $\mathrm{mZN}$, IIF and DIF was $0 \%, 3.8 \%, 4.7 \%$ and $0.4 \%$ and in dogs $0 \%, 0.6 \%, 6.4 \%$ and $0.6 \%$, respectively. The parasite was not detected in goats.

Conclusion: Results from the present study showed that IIF performed better diagnosis of Giardia and Cryptosporidium, and that the $\mathrm{mZN}$ can be used as an alternative for Cryptosporidium because of the high cost of IIF. There is a need for identification of genotypes or subtypes of these parasites through application of molecular techniques in order to determine their zoonotic potential, and we advocate a 'one health' approach in the control and prevention of these parasites.

Keywords: zoonoses; Giardia; Cryptosporidium; dogs; calves; goats; Mozambique.

\section{Introduction}

Protozoan species from the genus Giardia and Cryptosporidium are known to infect domestic and wild animals (Taylor, Coop \& Wall 2007) and are implicated as causative agents of diarrhoea in children, and as opportunistic infections in HIV-positive patients (Fayer, Morgan \& Upton 2000; Irisarri-Gutiérrez et al. 2017; Morgan et al. 2000; Pedersen et al. 2014; Sow et al. 2016; Wang et al. 2018). In domestic animals, the parasites are mainly prevalent in neonates and young animals (Baroudi et al. 2018; De Waal 2012; Hamnes et al. 2006) with consequent economic loss because of different levels of morbidity and mortality (De Graaf et al. 1999) particularly when they occur in concomitant infections with helminthic infections (Taylor et al. 2007). There has been a description of two subtypes of Cryptosporidium parvum (Baroudi et al. 2018; Fayer et al. 2000; Santana et al. 2018; Squire et al. 2017) and multiple genotypes within the species Giardia duodenalis (Ebner et al. 2015; Feng \& Xiao 2011; Itagaki et al. 2005; Santín, Trout \& Fayer 2007; Sommer et al. 2018), and only a few are of zoonotic significance.

Depending on the purpose of the study, different techniques can be applied for the diagnosis of Giardia and Cryptosporidium. Direct smears with or without staining and concentration techniques are mainly used routinely in the laboratory, and despite the relatively low cost, they have a disadvantage of low sensitivity (Cheesbrough 1987; De Waal 2012). In view of this limitation, immunological techniques based on the detection of antigens such as enzyme-linked immunosorbent assay (ELISA), the immunofluorescence (IF) staining method and the molecular test polymerase chain reaction (PCR) which detects the parasite deoxyribonucleic acid (DNA) have been applied in epidemiological studies, and they have proved to be more sensitive and

Copyright: (c) 2019. The Authors. Licensee: AOSIS. This work is licensed under the Creative Commons Attribution License. 
specific (Geurden et al. 2008; Gómez-Couso, MéndezHermida \& Ares-Mazás 2006; Soares \& Tasca 2016).

Studies conducted in Mozambique have reported prevalence of $8.1 \%$ for Giardia intestinalis and $7.1 \%$ for Cryptosporidium spp. in humans (Irisarri-Gutiérrez et al. 2017). Mixed helminths infections of Toxocara canis and Ancylostoma spp. in dogs were reported by Cruz and Silva (1971) and Santos, Nhantumbo and Alho (2013); however, there was no reference to Giardia and Cryptosporidium spp. The objective of this study was to determine the prevalence of Giardia and Cryptosporidium in dogs, cattle and goats in the Magude District of Maputo Province, Mozambique.

\section{Materials and methods \\ Study area}

The study was conducted between February and September 2015 in the localities of the Magude District (Figure 1), Maputo Province, Mozambique, namely Magude Sede, Motaze, Mapulanguene, Panjane and Mahele. The climate in the study area is dry sub-tropical, with an annual temperature average of $22{ }^{\circ} \mathrm{C}-24{ }^{\circ} \mathrm{C}$ and the annual rainfall average of $630 \mathrm{~mm}$ (MAE 2005). Livestock production and agriculture associated with animal traction are the main livelihoods of

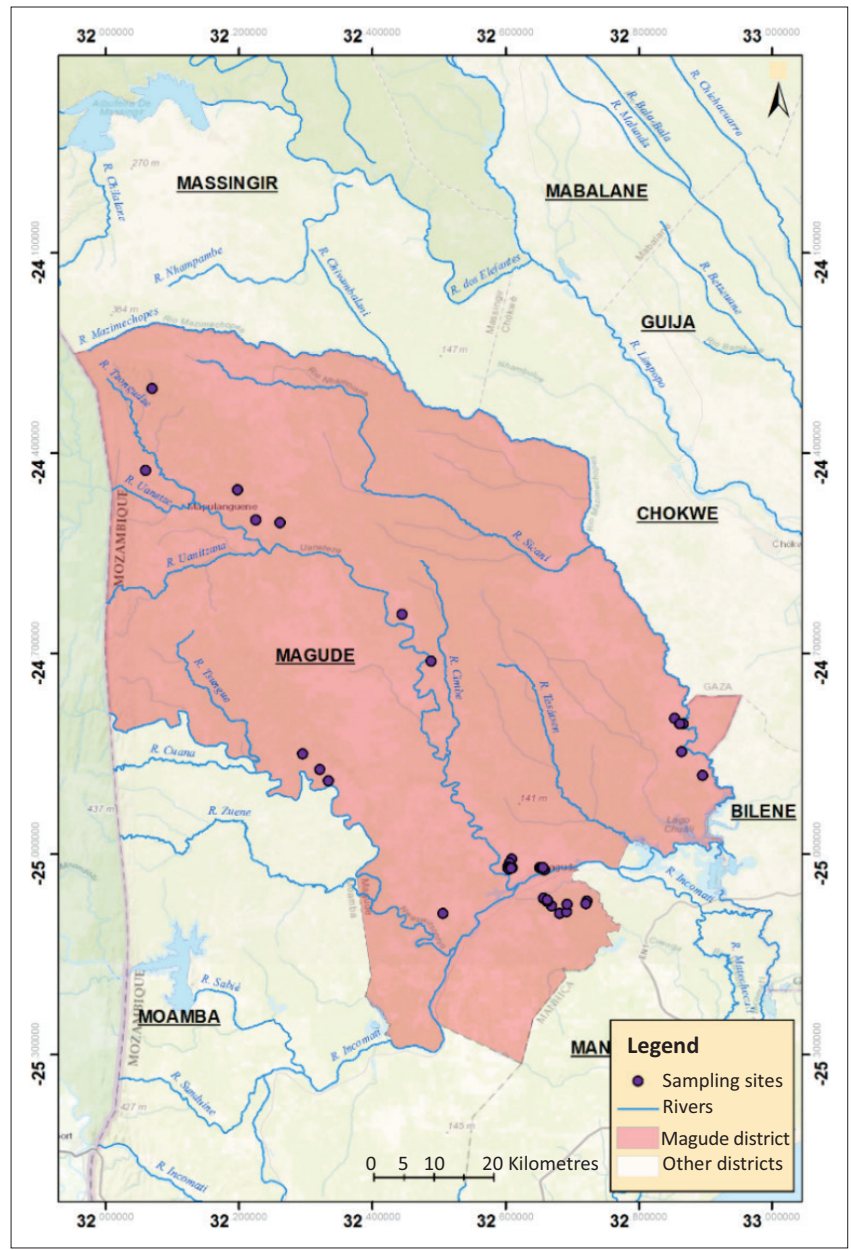

FIGURE 1: Map of Magude District and localities where dog and livestock samples were collected. the community (INE 2009). In the district, cattle are reared extensively, goats are housed at night and released in the morning to the communal grazing areas, and dogs are bred freely with many of them trained to shepherd cattle in grazing areas.

\section{Sample collection and laboratory analysis}

A total of 696 faecal samples were collected from the rectum of calves $(n=480)$, goat kids $(n=60)$ and dog pups $(n=156)$ all less than 7 months of age using a latex glove. Animals belonging to households pre-identified by the local veterinary technician were randomly selected at dip tanks during vaccination campaigns for calves, goats and dogs and a consent form was sought by each owner before sample collection. Sample consistence was classified as normal (soft to hard) or diarrheic (watery) and then transferred into tubes with caps which were labelled with individual details of each animal (animal species, age if possible and identification number) and transported in a cooler box to the Parasitology Laboratory, Faculty of Veterinary Medicine, Eduardo Mondlane University in Maputo, Mozambique, and kept at $4{ }^{\circ} \mathrm{C}$ until processed. A questionnaire was designed for dog owners and livestock farmers to collect information regarding animal husbandry, housing conditions, drinking water sources, feeding, treatment against parasitic infections and use of faeces in agricultural practices.

\section{Copromicroscopic analysis}

Faecal samples were processed for the detection of Giardia and Cryptosporidium (oo)cysts using the Willis flotation technique as described by Ueno and Gonçalves (1998). Identification of (oo)cysts was performed using morphological characteristics as described by Taylor et al. (2007). To concentrate the (oo)cysts in faecal samples, the formol-ether technique was used as described by Cheesbrough (1987). The pellet obtained from the concentration was used to prepare thin smears that were stained by the modified Ziehl-Neelsen (mZN) method as described by Cheesbrough (1987) and observed under an optical microscope at $100 \times$ magnification for the presence or absence of Cryptosporidium oocysts. The remainder of the pellet was transferred to Eppendorf tubes and preserved at $-20{ }^{\circ} \mathrm{C}$ for further processing for the detection of Cryptosporidium and Giardia by direct and indirect IF tests (DIF and IIF).

\section{Direct and indirect immunofluorescence}

The DIF test was carried out using a kit (MERIFLUOR ${ }^{\circledR}$ Cryptosporidium or Giardia; Meridian Diagnostic, United States [US]) according to the manufacturer's specification. All dog and goat samples were analysed; however, because of the lack of resources, only 237 calf samples were randomly selected and analysed by this technique.

The IIF test was conducted in all faecal samples except those from goats because the secondary antibody was 
derived from goats. For this technique, $25 \mu \mathrm{L}$ of concentrated faeces by formol-ether method was transferred to an IF slide. This was left to dry for approximately 5 minutes and fixed with absolute methanol. Approximately $50 \mu \mathrm{L}$ of primary antibody (Anti-Cryptosporidium parvum $\mathrm{mAb}$, Abnova and anti-Giardia lamblia pAb, Abnova, Europe) diluted in (3\%) bovine serum albumin (BSA) in phosphatebuffered saline (PBS) (1:500) was added to the smear, incubated for $1 \mathrm{~h}$ in a wet chamber and then washed three times in PBS Tween-20 (0.05\%). One drop of the secondary antibody coupled to fluorescein (Goat pAb to Cryptosporidium paroum oocyst and Giardia cysts or FITC, Abcam) diluted in 3\% BSA in PBS (1:1000) was added to the smear, incubated in the dark for $30 \mathrm{~min}$ and washed three times to remove the excess of fluorescein. To obtain the optimal dilution of the secondary antibody, serial dilutions were made starting from 1:10. A mounting reagent was added to the slide, covered with a coverslip and observed under a fluorescence microscope $(100 \times)$.

\section{Data analysis}

A sample was considered positive if at least one cyst or oocyst of Giardia or Cryptosporidium was identified in the slide. The prevalence (\%) was calculated as the number of positive samples divided by the total number of samples analysed multiplied by 100 (Thrusfield 1999). To analyse differences in the prevalence of Giardia and Cryptosporidium among the localities of the Magude District, a general linear multivariate model was applied in Statistical Package for the Social Sciences (SPSS) version 20.0 and $p<0.05$ was considered to be statistically significant. MediCalc software was used to calculate the sensitivity and specificity of $\mathrm{mZN}$ and IIF with the DIF test used as a gold standard.

\section{Ethical considerations}

This research was approved by the Scientific board of the Veterinary Faculty, Eduardo Mondlane University, Maputo, Mozambique.

\section{Results}

Giardia cysts were detected in calves, young goats and pups and Cryptosporidium oocysts in calves and dogs, as shown in Table 1. Prevalence values of Giardia and Cryptosporidium were high according to the IIF test in pups (8.3\%, CI: 8.0-8.5) (6.4\%, CI: 6.1-6.6) and calves $(8.1 \%$, CI: 7.9-8.3) (4.7\%, CI: 4.5-4.8), respectively. Following this technique, the prevalence of Giardia by the DIF test was 5.7\% (CI: 5.4-5.9) in pups, 6.0\% (CI: 5.8-6.2) in calves and Cryptosporidium by the mZN test in calves was $3.8 \%$ (CI: 3.6-3.9). In general, high prevalence values of Giardia spp. and Cryptosporidium spp. were recorded in the locality of Magude Sede for calves and dogs by IIF and the lower in the locality of Mahele for Giardia, and this association was significant $(p<0.05)$ as represented in Table 1 . Neither of these parasites was detected in dogs from Motaze and Mahele. The prevalence rate of Giardia spp. in goat kids from Motaze and Magude Sede was the same (6.66\%) and in other localities, no positive was detected in this animal species.

All samples collected in calves and goat kids had normal consistency, whilst three of the 156 samples from pups were diarrhoeic (1.9\%) and from these, only one was positive for Giardia trophozoites $(0.6 \%)$ by the Willis method.

The sensitivity and specificity of IIF, Willis and mZN are presented in Table 2. The mZN method showed high sensitivity (100\%) and specificity (96.20\% and 100\%) to detect Cryptosporidium oocysts in calves and dogs, respectively. The IIF method showed high sensitivity and specificity to both parasites, the sensitivity ranging between $88.89 \%$ and $100 \%$, and the specificity between $95.38 \%$ and $98.51 \%$ for Giardia spp.; with a sensitivity of $100 \%$ and specificity of $93.15 \%$ and 93.9\% for Cryptosporidium spp.

Other gastrointestinal helminths were observed in dog samples by the Willis method, namely Ancylostoma spp. with a prevalence of $60.3 \%$ (CI: 59.8-60.7) followed by Toxocara spp. (5.8\% [CI: 5.6-5.9]), Trichuris vulpis (1.3\% [CI: 1.2-1.4]), Spirocerca lupi 0.6\% ([CI: 0.5-0.7]) and Taeniidae (1.9\% [CI: 1.8-2.0]). In calves and goats, respectively, strongylid eggs were observed with prevalences of $50.8 \%$ (CI: 50.2-51.3) and $31.6 \%$ (CI: 30.5-32.6), Eimeria spp. with 17.5\% (CI: 17.1-17.8) and 41.6\% (CI: 40.4-42.7) and Moniezia spp. with $3.3 \%$ (CI: 3.1-3.4) and $11.6 \%$ (CI: 10.8-12.3).

TABLE 1: Prevalence (\%) of Giardia spp. and Cryptosporidium spp. in calves, goat kids and dog pups in different localities of the Magude District, Mozambique.

\begin{tabular}{|c|c|c|c|c|c|c|c|c|c|c|c|c|}
\hline \multirow[t]{3}{*}{ Locality } & \multicolumn{5}{|c|}{ Calves } & \multirow{3}{*}{$\begin{array}{c}\text { Goat kids } \\
\text { Giardia } \\
\text { DIF }\end{array}$} & \multicolumn{6}{|c|}{ Pups } \\
\hline & \multicolumn{2}{|c|}{ Giardia } & \multicolumn{3}{|c|}{ Cryptosporidium } & & \multicolumn{3}{|c|}{ Giardia } & \multicolumn{3}{|c|}{ Cryptosporidium } \\
\hline & DIF & IIF & $\mathrm{mZN}$ & DIF & IIF & & Willis & DIF & IIF & $\mathrm{mZN}$ & DIF & IIF \\
\hline Motaze & $2(0.8)$ & $2(0.4)$ & $4(0.8)$ & $1(0.4)$ & $9(1.8)$ & $4(6.66)$ & 0 & 0 & 0 & 0 & 0 & 0 \\
\hline Mahele & 0 & $1(0.2)^{*}$ & $2(0.4)$ & 0 & $3(0.6)$ & 0 & 0 & 0 & 0 & 0 & 0 & 0 \\
\hline Mapulanguene & $2(0.8)$ & $5(1.0)$ & $1(0.2)$ & 0 & $2(0.4)$ & 0 & 0 & $3(1.9)$ & $2(1.3)$ & 0 & 0 & 0 \\
\hline Panjane & 0 & $6(1.25)$ & $3(0.6)$ & 0 & $5(1.0)$ & 0 & 0 & 0 & $1(0.64)$ & 0 & 0 & $1(0.64)$ \\
\hline Magude Sede & $10(4.2)$ & $25(5.2)$ & $8(1.6)$ & 0 & $4(0.8)$ & $4(6.66)$ & $1(0.64)$ & $6(3.8)$ & $10(6.4)$ & $1(0.64)$ & $1(0.64)$ & $9(5.8)$ \\
\hline Total & $14(6.0)$ & $39(8.1)$ & $18(3.8)$ & $1(0.4)$ & $23(4.7)$ & $8(13.3)$ & $1(0.64)$ & $9(5.7)$ & $13(8.3)$ & $1(0.64)$ & $1(0.64)$ & $10(6.4)$ \\
\hline Total Cl & $5.8-6.2$ & $7.9-8.3$ & $3.6-3.9$ & $0.35-0.44$ & $4.5-4.8$ & $12.5-14.0$ & $0.52-0.67$ & $5.4-5.9$ & $8.0-8.5$ & $0.52-0.67$ & $0.52-0.67$ & $6.1-6.6$ \\
\hline$N$ & 237 & 480 & 480 & 237 & 480 & 60 & & 156 & & & 156 & \\
\hline
\end{tabular}

DIF, direct immunofluorescence; IIF, indirect immunofluorescence; $\mathrm{mZN}$, modified Ziehl-Neelsen; Willis, flotation technique; $N$, number; $\mathrm{Cl}$, confidence interval.

$*, p$-value based on general linear model multivariate $(p=0.001)$. 


\section{Discussion}

The present study focussed on the diagnosis of Giardia spp. and Cryptosporidium spp. in livestock and dogs using copromicroscopical and immunological tests. This is the first study in Mozambique reporting parasites of the genus Giardia and Cryptosporidium in a mixed farming (cropping and livestock) rural community set-up.

The prevalence of $3.75 \%$ for Cryptosporidium spp. in calves by $\mathrm{mZN}$ in the present study is slightly higher than the prevalence reported in calves from 3 to 8 months $(1.4 \%)$ and lower than the prevalence found in calves less than 3 months $(16.6 \%)$ in a study made by Mtambo et al. (1997) in Tanzania using the same diagnostic technique. The categorisation of animals into two groups compared to this study may have caused this discrepancy. On the other hand, on most of the farms sampled in this study, the animals were kept housed, thus increasing the chances of transmission between animals (Taylor et al. 2007). The same factor may have contributed to the high prevalence of Giardia spp. (49\%) and Cryptosporidium spp. (12\%) found by Hamnes et al. (2006) in calves between 3 and 183 days from Norway using IF tests. In addition, animals from this Norwegian study were exposed to lower temperature conditions (between $3.6^{\circ} \mathrm{C}$ and $14.0{ }^{\circ} \mathrm{C}$ ) than from the animals of the Magude District (between $18^{\circ} \mathrm{C}$ and $35^{\circ} \mathrm{C}$ ). High temperatures may reduce the viability of oocysts in the environment, whilst at temperatures near to $4{ }^{\circ} \mathrm{C}$, the parasites can remain viable for more than 1 month (Adam 2014), hence increasing the risk of infection.

In general, the prevalence rates were higher by IIF compared to the DIF test for both parasites. Following the IIF method by $\mathrm{mZN}$, the prevalence of Cryptosporidium in calves was also high and similar results were reported by Mtambo et al. (1992). The high sensitivity of IIF compared to mZN was also reported by Ortega-Mora et al. (1999) where same concentrated faecal samples of ewes were negative when analysed by mZN but positive by IIF.

Diarrhoea is a common clinical sign in animals infected by Giardia spp. and Cryptosporidium spp. (Dawson 2005; O'Donoghue 1995). The low incidence of animals with diarrhoea may suggest a low pathogenic significance of these parasitic infections in dog pups and calves in the Magude District. Besides the low pathogenic significance, other factors associated with the absence of clinical signs in positive animals are: (1) the phase of excretion of (oo)cysts because the peak coincides with the peak of animals with diarrhoea which is between the ages of 8-14 days for Cryptosporidium oocysts in cattle (Causapé et al. 2002; Olson et al. 2004) and between 2 and 4 weeks for Giardia (Geurden, Vercruysse \& Claerebout 2010); (2) development of an immunological response with the advancing age of animals (Huber, Bomfim \& Gomes 2005) and (3) the virulence of the genotype involved (Adam 2014). Although it was not possible to confirm the species and genotypes of Cryptosporidium and Giardia based on the techniques used, the zoonotic potential of these 
parasites should be taken into consideration, especially for Cryptosporidium spp. which is an opportunist in immunecompromised individuals such as those who are HIV-positive (Morgan et al. 2000). In Mozambique, Clavero et al. (1999) isolated Cryptosporidium spp. in HIV-infected humans.

The evaluation of sensitivity and specificity for Willis, mZN and IIF techniques compared to the DIF test showed a high sensitivity $(100 \%)$ and specificity $(96 \%-100 \%)$ for the mZN test in the detection of Cryptosporidium infections. Results from our study indicate that the mZN technique is highly reliable in the diagnosis of Cryptosporidium spp. in faecal samples. Studies conducted by Zaglool et al. (2013) and Quílez et al. (1996) in the diagnosis of Cryptosporidium spp. by mZN test indicated low sensitivities $(73.3 \%$ and $79.3 \%$, respectively) and a specificity approximating to the present study ( $95 \%$ and $100 \%$, respectively). The high sensitivity of the mZN test to detect Cryptosporidium spp. in this study can be attributed to the concentration of oocysts in faecal samples using the formalin-ether technique prior to analysis by subsequent tests. Salleh et al. (2014) demonstrated that the sensitivity of $\mathrm{mZN}$ can be improved by the application of concentration techniques.

In general, the sensitivity of IIF and mZN tests in the detection of Cryptosporidium spp. was similar (100\%) in this study, these results were also similar to findings by Rimhanen-Finne et al. (2007). Despite the similarity of results, the choice of diagnostic technique often depends on the availability of resources, time and the objective to be reached (diagnosis of specific parasite or multiple parasites) (Chalmers 2014). In the IIF technique specific antibodies against antigens produced by the parasite are used making it easy to read owing to the incidence of the fluorescent light in oo(cysts), indicated especially in cases of a low intensity of infections (Robertson 2014). The disadvantage of $\mathrm{mZN}$ staining is that the oocysts may be easily confused with faecal debris that take up the stains (Casemore, Armstrong \& Sands 1985). The efficiency of IIF compared to mZN was reported by Ortega-Mora et al. (1999) where the concentrated faecal samples of ewes were negative when analysed by mZN and positive by IIF.

Ancylostoma spp. (60.25\%) and Toxocara spp. (5.76\%) diagnosed in dogs of the Magude District are of zoonotic potential and the epidemiology of this parasite is mainly associated with the high biotic potential of females and with transmammary infection by which larvae are transmitted to the offspring from the bitch (Taylor et al. 2007; Urquhart et al. 1998). The lower prevalence of Toxocara spp. compared with Ancylostoma spp. can be justified by the possible presence of animals with larvae in somatic tissues in which, instead of the larvae developing, maturing and producing eggs, they remain dormant in different tissues, and thus, there is a reduction or absence of eggs in faeces (Taylor et al. 2007).

There is a need for additional studies aimed at applying molecular techniques to identify the genotypes and subtypes of Giardia and Cryptosporidium involved in order to determine their zoonotic potential and to adopt effective control and prevention measures.

\section{Acknowledgements}

The authors are grateful to the financier UEM/ASDI 'Impact of Zoonotic Diseases on Public Health and Animal Production in Mozambique'. The authors are also thankful to all the collaborators from South Africa (Ms Pulane Malatji and Dr Oliver Zishiri) and from Mozambique (the Agricultural technician from the Magude District and the Parasitology Laboratory technician) involved in the sample collection.

\section{Competing interests}

The authors declare that they have no financial or personal relationships that may have inappropriately influenced them in writing this article.

\section{Authors' contributions}

R.D.M., J.L., S.M.d.S.A. and S.M. conceived and designed the experiments R.D.M. and B.L. collected the samples from the field. R.D.M., S.M.d.S.A. and M.P.M. performed the experiments. R.D.M. and A.P.J. analysed the data. R.D.M. wrote the article. All authors read and approved the final manuscript.

\section{Funding information}

The research was funded by UEM/ASDI 'Impact of Zoonotic Diseases on Public Health and Animal Production in Mozambique'.

\section{Data availability statement}

Data sharing is not applicable to this article as no new data were created or analysed in this study.

\section{Disclaimer}

The views and opinions expressed in this article are those of the authors and do not necessarily reflect the official policy or position of any affiliated agency of the authors.

\section{References}

Adam, R.D., 2014, 'Protozoa-Giardia lamblia', University of Arizona College of Medicine, Encyclopedia of Food Safety 2, 37-43. https://doi.org/10.1016/B9780-12-378612-8.00135-9

Baroudi, D., Hakem, A., Adamu, H., Amer, S., Khelef, D., Adjou, K. et al., 2018, 'Zoonotic Cryptosporidium species and subtypes in lambs and goat kids in Algeria', Parasites \& Vectors 11(1), 582. https://doi.org/10.1186/s13071-018-3172-2

Casemore, D.P., Armstrong, M. \& Sands, R.L., 1985, 'Laboratory diagnosis of cryptosporidiosis', Journal of Clinical Pathology 38(12), 1337-1341. https://doi. org/10.1136/jcp.38.12.1337

Causapé, A.C., Quílez, J., Sánchez-Acedo, C., Del Cacho, E. \& López-Bernad, F., 2002, 'Prevalence and analysis of potential risk factors for Cryptosporidium parvum infection in lambs in Zaragoza (northeastern Spain)', Veterinary Parasitology 104(4), 287-298. https://doi.org/10.1016/S0304-4017(01)00639-2

Chalmers, R.M., 2014, Cryptosporidium; Encyclopedia of Food Microbiology, vol. 1, pp. 533-545, Elsevier.

Cheesbrough, M., 1987, Medical laboratory manual for tropical countries, vol. 1, 2nd edn., pp. 187-217, Cambridge University Press, New York. 
Clavero, A.O., Verdú, M.E., Pemán, J., Dario, R. \& Gobernado, M., 1999, 'Human intestinal infection due to coccidia in Mozambique: Two cases', Acta Tropica 72(1), 25-29. https://doi.org/10.1016/S0001-706X(98)00079-5

Cruz, J.A. \& Silva, J.A., 1971, 'Contribuição para o estudo dos helmintes parasitas dos vertebrados de Moçambique', in Memórias da junta de investigação do Ultramar, Lisboa, 2a série número 65, pp. 409-410.

Dawson, D., 2005, 'Foodborne protozoan parasites', International Journal of Food Microbiology 103(2), 207-227. https://doi.org/10.1016/j.ijfoodmicro.2004. 12.032

De Graaf, D.C., Vanopdenbosch, E., Ortega-Mora, L.M., Abbassi, H. \& Peeters, J.E., 1999, 'A review of the importance of cryptosporidiosis in farm animals', International Journal for Parasitology 29(8), 1269-1287. https://doi.org/10.1016/ S0020-7519(99)00076-4

De Waal, T., 2012, 'Advances in diagnosis of protozoan diseases', Veterinary Parasitology 189(1), 65-74. https://doi.org/10.1016/j.vetpar.2012.03.033

Ebner, J., Koehler, A.V., Robertson, G., Brad-bury, R.S., Haydon, S.R., Stevens, M.A et al., 2015, 'Genetic analysis of Giardia and Cryptosporidium from people in Northern Australia using PCR-based tools', Infection, Genetics and Evolution 36(December 2015), 389-395. https://doi.org/10.1016/j.meegid.2015.08.034

Fayer, R., Morgan, U. \& Upton, S.J., 2000, 'Epidemiology of Cryptosporidium: Transmission, detection and identification', International Journal for Parasitolog 30(12-13), 1305-1322. https://doi.org/10.1016/S0020-7519(00)00135-1

Feng, Y. \& Xiao, L., 2011, 'Zoonotic potential and molecular epidemiology of Giardia species and giardiasis', Clinical Microbiology Reviews 24(1), 110-140. https://doi. org/10.1128/CMR.00033-10

Geurden, T., Berkvens, D., Casaert, S., Vercruysse, J. \& Claerebout, E., 2008, 'A Bayesian evaluation of three diagnostic assays for the detection of Giardia duodenalis in symptomatic and asymptomatic dogs', Veterinary Parasitology 157(1-2), 14-20. symptomatic and asymptomatic dogs', Veterinar.//doi.org/10.1016/j.vetpar.2008.07.002

Geurden, T., Vercruysse, J. \& Claerebout, E., 2010, 'Is Giardia a significant pathogen in production animals', Experimental Parasitology 124(1), 98-106. https://doi. org/10.1016/j.exppara.2009.03.001

Gómez-Couso, H., Méndez-Hermida, F. \& Ares-Mazás, E., 2006, 'Levels of detection of Cryptosporidium oocysts in mussels (Mytilus galloprovincialis) by IFA and PCR methods', Veterinary Parasitology 141(1-2), 60-65. https://doi.org/10.1016/j. vetpar.2006.04.015

Hamnes, I.S., Gjerde, B. \& Robertson, L., 2006, 'Prevalence of Giardia and Cryptosporidium in dairy calves in three areas of Norway', Veterinary Parasitology 140(3-4), 204-216. https://doi.org/10.1016/j.vetpar.2006.03.024

Huber, F., Bomfim, T.C.B. \& Gomes, R.S., 2005, 'Comparison between natural infection by Cryptosporidium sp., Giardia sp. in dogs in two living situations in the West Zone of the municipality of Rio de Janeiro', Veterinary Parasitology 130(1-2), 69-72. https://doi.org/10.1016/j.vetpar.2005.03.012

Instituto Nacional de Estatística - INE, 2009, $2^{a}$ Edição do Retrato da Província de Maputo, Delegação Provincial do Instituto Nacional de Estatística, Maputo.

Irisarri-Gutiérrez, M.J., De Mingo, M.H., De Lucio, A., Gil, H., Morales, L., Seguí, R. et al., 2017, 'Association between enteric protozoan parasites and gastrointestina illness among HIV-and tuberculosis-infected individuals in the Chowke district, southern Mozambique', Acta tropica 170(June 2017), 197-203. https://doi. org/10.1016/j.actatropica.2017.03.010

Itagaki, T., Kinoshita, S., Aoki, M., Itoh, N., Saeki, H., Sato, N. et al., 2005, 'Genotyping of Giardia intestinalis from domestic and wild animals in Japan using glutamate dehydrogenase gene sequencing', Veterinary Parasitology 133(4), 283-287. https://doi.org/10.1016/j.vetpar.2005.05.061

Ministério da Administração Estatal - MAE, 2005, 'Perfíl do Distrito de Magude, Provínvia de Maputo', Republica de Moçambique, pp. 3-4.

Morgan, U., Weber, R., Xiao, L., Sulaiman, I., Thompson, R.C.A., Ndiritu, W. et al., 2000 'Molecular characterization of Cryptosporidium isolates obtained from human immunodeficiency virus-infected individuals living in Switzerland, Kenya, and the United States', Journal of Clinical Microbiology 38(3), 1180-1183.

Mtambo, M.M.A., Nash, A.S., Blewett, D.A. \& Wright, S., 1992, 'Comparison of staining and concentration techniques for detection of Cryptosporidium oocysts in cat faecal specimens', Veterinary Parasitology 45(1-2), 49-57. https://doi. org/10.1016/0304-4017(92)90026-6

Mtambo, M.M.A., Sebatwale, J.B., Kambarage, D.M., Muhairwa, A.P., Maeda, G.E., Kusiluka, L.J.M. et al., 1997, 'Prevalence of Cryptosporidium spp. oocysts in cattle and wildlife in Morogoro region, Tanzania', Preventive Veterinary Medicine 31(3-4), 185-190. https://doi.org/10.1016/S0167-5877(96)01130-0

O'Donoghue, P.J., 1995, 'Cryptosporidium and Cryptosporidiosis in Man and Animals', International Journal for Parasitology 25(2), 139-195. https://doi. org/10.1016/0020-7519(94)E0059-V
Olson, M.E., O'Handley, R.M., Ralston, B.J., McAllister, T.A. \& Thompson, R.C.A., 2004, 'Update on Cryptosporidium and Giardia infections in cattle', Trends in Parasitology 20(4), 185-191. https://doi.org/10.1016/j.pt.2004.01.015

Ortega-Mora, L.M, Requejo-Fernández, J.A, Pilar-Izquierdo, M. \& Pereira-Bueno, J., 1999, 'Role of adult sheep in transmission of infection by Cryptosporidium parvum to lambs: Confirmation of periparturient rise', International Journal for Parasitology 29(8), 1261-1268. https://doi.org/10.1016/S0020-7519(99)00077-6

Pedersen, S.H., Wilkinson, A.L., Andreasen, A., Warhurst, D.C., Kinung'hi, S.M., Urassa, M. et al., 2014, 'Cryptosporidium prevalence and risk factors among mothers and infants 0 to 6 months in rural and semi-rural Northwest Tanzania: A prospective cohort study', PLoS Neglected Tropical Diseases 8(10), e3072. https://doi.org/10.1371/journal.pntd.0003072

Quílez, J., Sánchez-Acedo, C., Clavel, A., Del Cacho, E. \& López-Bernad, F. 1996, 'Comparison of an acid-fast stain and a monoclonal antibody-based immunofluorescence reagent for the detection of Cryptosporidium oocysts in faecal specimens from cattle and pigs', Veterinary Parasitology 2, 67(1-2), 75-81.

Rimhanen-Finne, R., Enemark, H.L., Kolehmainen, J., Toropainen, P. \& Hanninen, M.L., 2007, 'Evaluation of immunofluorescence microscopy and enzyme-linked immunosorbent assay in detection of Cryptosporidium and Giardia infections in asymptomatic dogs', Veterinary Parasitology 145(3-4), 345-348. https://doi. org/10.1016/j.vetpar.2007.01.008

Robertson, L.J., 2014, 'Giardia duodenalis; Encyclopedia of food microbiology', 2, 946-955, Elsevier.

Salleh, F.M., Moktar, N., Yasin, A.M., Al-Mekhlafi, H.M. \& Anuar, T.S., 2014, 'An improved stool concentration procedure for the detection of Cryptosporidium oocysts in Orang Asli stool samples', Journal of Microbiological Methods 106(November 2016), 143-145. https://doi.org/10.1016/j.mimet.2014.08.019

Santana, B.N., Kurahara, B., Nakamura, A.A., Camargo, V.S., Ferrari, E.D., Silva, G.S et al., 2018, 'Detection and characterization of Cryptosporidium species and genotypes in three chicken production systems in Brazil using different molecular diagnosis protocols', Preventive Veterinary Medicine 151(1), 73-78. https://doi. org/10.1016/j.prevetmed.2018.01.007

Santín, M., Trout, J.M. \& Fayer, R., 2007, 'Prevalence and molecular characterization of Cryptosporidium and Giardia species and genotypes in sheep in Maryland', Veterinary Parasitology 146(1-2), 17-24. https://doi.org/10.1016/j.vetpar.2007.01.010

Santos, I.F.C., Nhantumbo, B. \& Alho, P., 2013, 'Occurrence of Ancylostoma caninum and Toxocara canis in the Veterinary School Hospital (HEV) (2001-2010), Maputo, Mozambique', Revista Científica Eletrônica de Medicina Veterinária 21, 1679-7353.

Soares, R. \& Tasca, T., 2016, 'Giardiasis: An update review on sensitivity and specificity of methods for laboratorial diagnosis', Journal of Microbiological Methods 129(October 2016), 98-102. https://doi.org/10.1016/j.mimet.2016.08.017

Sommer, M.F., Rupp, P., Pietsch, M., Kaspar, A. \& Beelitz, P., 2018, 'Giardia in a selected population of dogs and cats in Germany - Diagnostics, coinfections and assemblages', Veterinary Parasitology 249, 49-56. https://doi.org/10.1016/j. vetpar.2017.11.006

Sow, S.O., Muhsen, K., Nasrin, D., Blackwelder, W.C., Wu, Y., Farag, T.H. et al., 2016, 'The burden of Cryptosporidium diarrheal disease among children $<24$ months of age in moderate/high mortality regions of sub-Saharan Africa and South Asia, utilizing data from the Global Enteric Multicenter Study (GEMS) ', PLoS Neglected Tropical Diseases 10(5), e0004729. https://doi.org/10.1371/journal.pntd.0004729

Squire, S.A., Yang, R., Robertson, I., Ayi, I. \& Ryan, U., 2017, 'Molecular characterization of Cryptosporidium and Giardia in farmers and their ruminant livestock from the Coastal Savannah zone of Ghana', Infection, Genetics and Evolution 55, 236-243. https://doi.org/10.1016/j.meegid.2017.09.025

Taylor, M.A., Coop, R.L. \& Wall, R.L., 2007, ' Veterinary parasitology, 3rd edn., pp. $213-219,802,803,942,943,945,1176,1197,1198$, Blackwell Publishing Hoboken, New Jersey.

Thrusfield, M., 1999, Veterinary epidemiology, 2nd edn., pp. 179-212, Blackwell, Oxford.

Ueno, H. \& Gonçalves, P.C., 1998, Manual para diagnóstico das Helmintoses de Ruminantes, $4^{\mathrm{a}}$ edição, pp. 12-14, Japan International Cooperation Agency.

Urquhart, G.M., Armour, J., Duncan, J.L., Dunn, A.M. \& Jennings, F.W., 1998, Parasitologia veterinária, 2nd edn., pp. 46, 47, 60, 61, 183-204, Blackwell Science, New Jersey.

Wang, R.J., Li, J.Q., Chen, Y.C., Zhang, L.X., Xiao, L.H., 2018, 'Widespread occurrence of Cryptosporidium infections in patients with HIV/AIDS: Epidemiology, clinical feature, diagnosis, and therapy', Acta Tropica 187, 257-263. https://doi. org/10.1016/j.actatropica.2018.08.018

Zaglool, D.A.M., Mohamed, A., Khodari, Y.A.W. \& Farooq, M.U., 2013, 'Crypto-Giardia antigen rapid test versus conventional modified Ziehl- Neelsen acid fast staining method for diagnosis of cryptosporidiosis', Asian Pacific Journal of Tropical Medicine 6(3), 212-215. https://doi.org/10.1016/S1995-7645(13)60025-5 